\title{
Studies on characterization of corn cob based nanoparticles
}

\author{
Samit Kumar, Yuvraj Singh Negi*, Jugmendra Sain Upadhyaya
}

Polymer Science and Technology Program, Department of Paper Technology, Indian Institute of Technology Roorkee, Saharanpur Campus, Saharanpur 247001, U.P., India

*Corresponding author. Tel: (+91) 132 2714328; E-mail: yuvrajnegi@ gmail.com

Received: 13 Sept 2010, Revised: 8 Oct 2010 and Accepted: 11 Oct 2010

\section{ABSTRACT}

Corn cobs (central part of maize) are either treated as waste or burnt as fuel causing environmental concern. In order to achieve its value addition in new research areas, corn cob can be processed chemically to find ways to generate new end products with added values at very low price. Cellulose-based nanoparticles (CPNs) have an ability to remain intact in stomach environment and small intestine together with the presence of specific enzymes produced by cellulytic bacteria (ruminococus) for colon biodegradability and makes this biopolymer a suitable raw material for the biomedical field, particularly as a colon-specific drug carrier. Cellulose-based nanoparticles (CPNs) were prepared from corn cob raw material by treating it with sodium hydroxide in the range $0-24 \%$ of sodium hydroxide concentration, oven dry basis at $165^{\circ} \mathrm{C}$ for $1.5 \mathrm{~h}$ at liquor to solid ratio of 4.5:1. The sample obtained at the optimised condition ( $18 \% \mathrm{NaOH}$ concentration, oven dry basis of raw materials) was washed with deionised water, disintegrated and filtered through 80 mesh screens. Powder thus obtained was delignified by acidified sodium chlorite and dried in a vacuum oven to constant weight. Dried powder was further separated by 270 mesh screens. An average particle size approximately equal to $22 \mathrm{~nm}$ was obtained by using Transmission Electron Microscopy (TEM). Its crystallinity, functional group and agglomerated particle size was determined by X-ray Diffraction (XRD), Fourier Transform Infrared (FT-IR) and Scanning Electron Microscopy (SEM) techniques respectively. Copyright (C) 2010 VBRI press.

Keywords: Corn cob; lignocellulosic materials; nanoparticles; TEM; XRD; SEM; FT-IR spectroscopy.

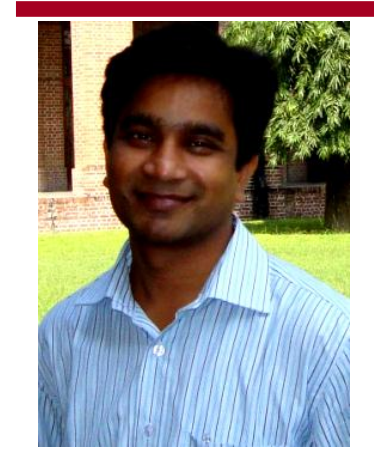

Samit Kumar obtained his bachelor degree in science from IGNOU, New Delhi, India and master degree in organic chemistry from Patna University, Patna, India. $\mathrm{He}$ has registered for $\mathrm{PhD}$ at Department of Paper Technology, IIT Roorkee, India. His main research interests are biopolymer and their application specifically in biomedical area.

Yuvraj Singh Negi is Associate Professor, Polymer Science and Technology Program in the Department of Paper Technology (DPT), IIT Roorkee, India since 2005. He did his Ph.D. in 1983 from IIT Delhi and served for more than twenty years as Industrial/Scientific $\mathrm{R}$ \& $\mathrm{D}$ polymer Research Scientist/Manger in Japan and India. He has wide experience in the field of Polymer Synthesis, Characterization and Applications of polymers and his research work has been patented and published in national \& international journals of repute and conference proceedings. He has been involved for more than Nine years in industrial Polymer R \& D sectors in India and abroad. He has also handled sponsored and Industrial in-house projects successfully.

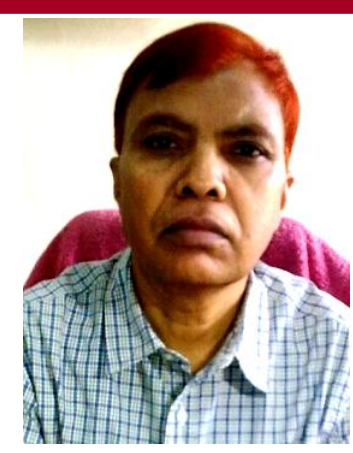

J.S. Upadhyaya is Professor in Department of Paper Technology (DPT), IIT Roorkee, India. He did his Ph.D. in 1976 from university of Roorkee, India and joined the department of Paper Technology in 1979 and took over as the Head, DPT, IIT Roorkee, India and completed two tenure of Headship from January 2001 to December 2003 and January 2007 to December 2009. He has wide experience in the field of pulp and paper technology. He has published more than 170 research paper in various reputed national and international journals of high impact factor and also published various research papers in proceedings of the various national and international conferences. He has also handled sponsored research projects successfully.

\section{Introduction}

Nanotechnology has rapidly become an interdisciplinary field and one of the exciting research areas is the synthesis of cellulose-based nanoparticles (CNPs) from bioresources, especially from annual plants and agriculture crop residues such as corn cobs, corn grain, wheat stems, seed coats, and sugar cane stalks using top-down technologies. 
Cellulose is the world's most abundant natural, renewable, biodegradable polymer. It has been estimated that globally, $10^{10}$ to $10^{11}$ tonnes are synthesized and also destroyed each year. It is a polydispersed linear polymer of poly- $\beta$ (1, 4)-D-glucopyranose with a syndiotactic configuration [1]. Corn cobs, central part of maize (Zea mays) are either thrown out as waste or burnt, an application with low added value, causing environmental concern. So it is an exciting research area to use corn cob for chemical processing to obtain end products with added values worldwide at very low price [2]. Corn cob contains holocellulose, lignin and others in the approximate percentage of 73, 16 and 11 respectively. Concerning, specifically, the holocellulose from corn cobs, it has been demonstrated that such polymer presents a chemical composition of $\alpha$-, $\beta$-, and $\gamma$-cellulose in the proportion of 5.2:2.8:3.0 respectively on oven dry basis. By this investigation it has been demonstrated that corn cobs contain a considerable amount of $\alpha$-cellulose $(47.27 \%$ ) along with $\beta$-cellulose $(25.45 \%)$, comprised as degraded cellulose and $\gamma$-cellulose $(27.27 \%)$, consisting mainly of hemicelluloses on oven dry basis of holocellulose [2].

Cellulose-based nanoparticles (CNPs) are expected to have a wide range of applications because cellulose materials can self-assemble into well-defined architectures in multiple scales, from micro to nanosize. Moreover, cellulose is not only renewable but also a multifunctional raw material and is expected to be able to replace many non-renewable materials [3]. An important characteristic of cellulose-based nanoparticles is its ability to remain intact in the physiological stomach environment and small intestine. This property, together with the presence of specific enzymes produced by cellulytic bacteria like ruminococus [4-5] for colon biodegradability, makes this polymer a suitable raw material for the biomedical field, particularly as a colon-specific drug carrier [6]. The human colon contains a substantial mixed culture of bacteria estimated at $10^{10}$ to $10^{11} / \mathrm{g}$ colonic and faecal material, 99\% of which are anaerobes [7-8]. Most of these organisms are saccharolytic that is they derive their energy primarily from carbohydrate and its derivatives [9]. The rate of degradation of cellulose/drug absorption in colon depends also upon particle size, the finer the particle the more readily digestible [10] and laxation rate (frequency of defecation), less cellulose being digested in subjects who had more frequent bowel actions [11].

Because of the distal location of colon at the gastrointestinal tract, a colon specific drug delivery system should prevent drug release in the stomach and small intestine, and provide an abrupt commencement of drug release upon entry into the colon. For that purposes, nonstarch polysaccharides like CNPs remain undigested in the stomach and the small intestine and can only be degraded by the vast anaerobic colon cellulytic bacteria like ruminococus. Owing to these characteristics, CNPs may be considered as an efficient candidate of polymer as drug delivery carrier. CNPs prepared from corn cob can also improve the pharmacokinetic properties of drugs and thereby reduce toxic side effect. In view of the emergent demand and modernisation of pharmaceutical industries, nanoparticles of reduced dimension can bring substantial changes in therapeutic systems by developing improved pharmaceutical grade biopolymer. Thus, the objective of present study is focused on evaluating the use of corn cobs to prepare CNPs in narrow size distribution with an aim to explore possible colon-specific drug carrier.

\section{Experimental}

\section{Raw material}

The corn cob sample was collected from agricultural field locally (Dehradun, Uttarakhand, India) and it was milled into powder in a laboratory Wiley Mill, and fractions passing through 40 mesh $(400 \mu \mathrm{m})$ screens but retained on 80 mesh $(177 \mu \mathrm{m})$ screens was collected. Sample was airdried, homogenised in a single lot to avoid compositional differences among aliquots, and stored for compositional analysis.

The other lot of corn cob sample was chopped manually into 1.5 to $2.0 \mathrm{~cm}$ long and 0.25 to $0.5 \mathrm{~cm}$ thick pieces. This sample was also air-dried, homogenised in a single lot to avoid compositional differences among aliquots, and stored for chemical analysis.

\section{Analysis of raw material}

The chemical compositional data of the corn cob samples used as a raw material (as the average of four replicate analyses) is shown in Table 1. The results are expressed as weight percent of holocellulose ( $\alpha$-, $\beta$ - and $\gamma$-Cellulose), pentosans, Klason lignin, and ethanol-benzene solubles, by using TAPPI Standard Test Methods T $249 \mathrm{~cm}-00$ (T 203 cm-99), T 223 cm-01, T 222 om-06, T 204 cm-07 respectively. The other fractions, including uronic acids, acetyl groups, etc., were not determined, owing to their minor significance for the intention of this work.

Xylan is a major component of hemicellulose accounts for roughly one-third or second most abundant of renewable biomass in the plant kingdom. It constitutes approximately $28 \%$ of the dry biomass of woody tissues. The chemical structure of xylan in corn cob is mainly composed of D-glucuronic acid, L-arabinose and D-xylose in the approximate ratio of 2:7:19 [12].

Table 1. Compositions of Corn Cob (as the average of four replicate determinations)*

\begin{tabular}{lcc}
\hline & \multicolumn{1}{c}{ Fractions } & Weight \% \\
\hline Holocellulose & \multicolumn{2}{c}{73.04} \\
(a) $\quad \alpha$-Cellulose & 34.45 \\
(b) $\quad \beta$-Cellulose & 18.73 \\
(c) $\quad$-Cellulose & 19.84 \\
Pentosans (Xylan) & \multicolumn{2}{c}{28.23} \\
Total lignin & \multicolumn{2}{c}{16.03} \\
(a) Klason Lignin (Acid insoluble) & 14.01 \\
(b) Acid soluble lignin & 2.02 \\
Ethanol-Benzene soluble & \multicolumn{2}{|}{4.33} \\
Others (Difference) & \multicolumn{2}{c}{6.64} \\
\hline
\end{tabular}

*Results expressed as weight percent, oven dry basis of raw materials.

The holocellulose from corn cobs has been demonstrated to show chemical composition of $\alpha-, \beta-$, and 
$\gamma$-cellulose in the ratio of 5.2:2.8:3.0 respectively. By this investigation it has been demonstrated that corn cobs contain a considerable amount of $\alpha$-cellulose $(47.27 \%)$ along with $\beta$-cellulose, comprised as degraded cellulose $(25.46 \%)$ and $\gamma$-cellulose, consists mainly of hemicelluloses (27.27\%) is shown in Table 2.

Table 2. Chemical composition of holocellulose oven dry basis.

\begin{tabular}{ccc}
$\begin{array}{c}\alpha- \\
\begin{array}{c}\text { Cellulose } \\
(\%)\end{array}\end{array}$ & $\begin{array}{c}\beta- \\
\text { Cellulose } \\
(\%)\end{array}$ & $\begin{array}{c}\gamma^{-} \\
\text {Cellulose } \\
(\%)\end{array}$ \\
\hline 47.27 & 25.45 & 27.27 \\
\hline
\end{tabular}

\section{Alkaline treatment of raw material}

The mannually chopped sample of corn cob was treated in a WEVERK electically heated rotary digester of $0.02 \mathrm{~m}^{3}$ capacity having four bombs of 1 liter capacity each. The chips of corn cobs were treated with sodium hydroxide in the range 0 (i.e., autohydrolysis) to $24 \%$ of sodium hydroxide on oven dry basis, at a temperature $165{ }^{\circ} \mathrm{C}$ for $1.5 \mathrm{~h}$ at liquor to solid ratio of 4.5:1. After completion of the treatment, the samples were washed on a 270 mesh $(53 \mu \mathrm{m})$ screen for the removal of residual chemicals. The samples were disintegrated and screened through 80 mesh screens $(177 \mu \mathrm{m})$, and the screened product was washed, pressed, and crumbled. The samples were analysed for pentosans (T $223 \mathrm{~cm}-01$ ), lignin (T $22 \mathrm{om}-88$ ), screening rejects and yield by weight as per TAPPI Standard Test Methods (2007). The results are shown in Table 3.

Table 3. Effect of chemical treatment on residual lignin, Pentosan, screened yield, rejects and total yield (results expressed as weight percent, oven dry basis of raw material ${ }^{\#}$ and screened yield*)

\begin{tabular}{cccccccc}
\hline $\begin{array}{c}\mathrm{NaOH}^{\Theta} \\
(\%)\end{array}$ & $\begin{array}{c}\text { Reject }^{\#} \\
(\%)\end{array}$ & $\begin{array}{c}\text { Screened } \\
\text { yield }(\%)\end{array}$ & $\begin{array}{c}\text { Total yield }^{\#} \\
(\%)\end{array}$ & $\begin{array}{c}\text { Lignin }^{*} \\
(\%)\end{array}$ & $\begin{array}{c}\text { Lignin\# }^{\#}(\%) \\
{ }^{*}\end{array}$ & $\begin{array}{c}\text { Pentosans } \\
* \\
(\%)\end{array}$ & $\begin{array}{c}\text { Pentosans } \\
(\%)\end{array}$ \\
\hline 0 & 33.20 & 26.23 & 59.43 & 22.236 & 13.214 & 12.61 & 7.49 \\
2 & 43.32 & 23.70 & 67.02 & 18.276 & 12.249 & 25.69 & 17.22 \\
4 & 53.22 & 19.70 & 72.92 & 14.022 & 10.225 & 26.12 & 19.05 \\
6 & 43.10 & 24.72 & 67.82 & 11.377 & 7.716 & 28.89 & 19.59 \\
8 & 26.67 & 29.03 & 55.70 & 7.660 & 4.267 & 32.93 & 18.34 \\
10 & 19.68 & 33.41 & 53.09 & 7.248 & 3.848 & 35.25 & 18.71 \\
12 & 14.54 & 38.32 & 52.86 & 5.073 & 2.682 & 34.91 & 18.45 \\
14 & 10.67 & 42.17 & 52.84 & 4.080 & 2.156 & 34.77 & 18.37 \\
16 & 7.85 & 43.27 & 51.12 & 3.069 & 1.569 & 34.63 & 17.70 \\
18 & 4.20 & 45.41 & 49.61 & 1.626 & 0.807 & 34.46 & 17.10 \\
20 & 1.99 & 41.79 & 43.78 & 1.557 & 0.682 & 30.33 & 13.28 \\
22 & 1.52 & 37.66 & 39.18 & 1.371 & 0.537 & 26.81 & 10.51 \\
24 & 0.26 & 37.04 & 37.30 & 1.311 & 0.489 & 23.62 & 8.81 \\
\hline
\end{tabular}

Isolation and characterization of lignin

Milled wood lignin (MWL) was obtained after methanolbenzene extraction of the milled corn cob according to TAPPI Standard Test Methods T 222 om-06. Fourier transform infrared (FT-IR) spectroscopy was performed using a Nicolet spectrophotometer. Samples were ovendried at $105^{\circ} \mathrm{C}$ for $4 \mathrm{~h}$, mixed with $\mathrm{KBr}$ in a ratio of $1: 200$ $\mathrm{mg}$ (corn cob lignin: $\mathrm{KBr}$ ) and pressed under vacuum to form pellets. Absorbance was measured over a range from 4000 to $500 \mathrm{~cm}^{-1}$.

\section{Characterisation of nanoparticles}

FT-IR spectroscopy was performed using a Nicolet spectrophotometer. Samples were oven dried at $105^{\circ} \mathrm{C}$ for $4 \mathrm{~h}$, mixed with $\mathrm{KBr}$ in a ratio of 1:200 $\mathrm{mg}$ (corn cob-based nanoparticles: $\mathrm{KBr}$ ) and pressed under vacuum to form pellets.

High-resolution Transmission Electron Microscopy (TEM) was carried out with an FEI Technai G2 F20 microscope at $200 \mathrm{kV}$; the samples were air dried before using the TEM to characterise the size and morphology of the dried particles. For TEM observation, the samples were prepared in methanol at $100 \mu \mathrm{g} / \mathrm{mL}$ concentration and dispersed in an ultrasonicator for ten minutes. The samples for TEM analysis were obtained by placing a drop of the colloidal dispersion containing the corncob nanoparticles onto the carbon-coated copper grid. They were dried at room temperature and then examined using the TEM without any further modification. The particle sizes in morphology were measured using a scale bar in micrographs.

X-ray diffraction (XRD) of samples was recorded on a Bruker AXS D8 Advance diffractrometer with a scanning rate of $1^{\circ} \mathrm{C} / \mathrm{min}$ with $\mathrm{CuK} \alpha$ radiation source $(\lambda=1.54060$ $\AA$ ) operating at $40 \mathrm{kV}$ and $30 \mathrm{~mA}$. For that purposes finely powdered sample i.e. nanoparticles (NPs) placed in the central cavity of sample holder made up of polymethyl methacrylate (PMMA) were used for X-ray diffraction studies.

Scanning Electron Microscopy (SEM) was performed, using a FEI Quanta $200 \mathrm{~F}$ microscope. The samples were mounted on Au coated stubs and observed at $20 \mathrm{kV}$.

\section{Results and discussion}

Mechanism of depolymerisation of hemicelluloses (mainly xylan) during auto hydrolysis

The chemical degradation of cellulose by acid catalysis is a heterogeneous process that has several steps of the macromolecular chain scission to form low molecular weight products [13]. Physical and chemical aspects control the overall rate and efficiency of the depolymerisation process. It is well known that fiber structure of cellulose, determined by the strong H-bonding of the glucopyranose chains, provides its high chemical stability. Thus the cleavage of its $\beta$-1-4-glycosidic bonds will depend critically on the interaction of the acid catalyst and water with the cellulose chain structure. Crystalline regions of the solid cellulose are less accessible to reactive species and, therefore, are more difficult to hydrolyse. Whereas hemicellulose, the amorphous content, on the other hand, are easily penetrated by chemical species (i.e. acid hydrolysis) due to the local chain disorder which gives to this fraction a faster rate of depolymerisation.

Since, the equilibrium dissociation constant of water is a function of temperature, the concentration of $\mathrm{H}^{+}$and $\mathrm{OH}^{-}$ increases appreciably with temperature. At a temperature of $250{ }^{\circ} \mathrm{C}$, the concentration of $\mathrm{H}^{+}$and $\mathrm{OH}^{-}$is of $2.3 \times 10^{-6}$ mole/L [14]. This represents an increase of 23.3 times the concentration of both ions present at $25^{\circ} \mathrm{C}$.

$$
2 \mathrm{H}_{2} \mathrm{O}
$$

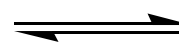

$\mathrm{H}_{3} \mathrm{O}^{+} \quad+$

$\mathrm{OH}^{-}$

When corncobs were subjected to a high-temperature $\left(165^{\circ} \mathrm{C}\right)$ treatment in water only then, acetyl groups of the 
acetylated xylan are cleaved to release acetic acid, which further increases the $\mathrm{H}_{3} \mathrm{O}^{+}$concentrations owing to this $\mathrm{pH}$ of the reaction medium further decreases and makes xylan easy to release from other components, such as lignin and cellulose. As a result, the average degree of polymerisation (DP) of xylan decreases and the solubility of xylan increase. Therefore, the pentosans content is found to be less $(7.49 \%$, oven dry basis of raw material) during auto hydrolysis as shown in Fig. 3 and Table 3.

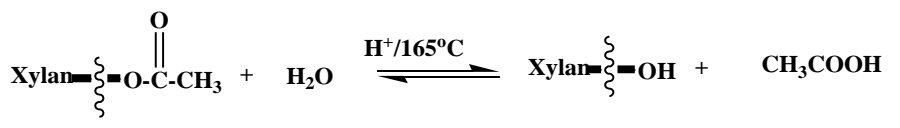

But as soon as concentration of $\mathrm{NaOH}$ increases, the medium of liquor changes from acidic to alkaline in nature, by which solubilisation of hemicelluloses were slowed down (because solubilisation of hemicelluloses were more susceptible to acidic condition). From Fig. 3 it is concluded that percentage of pentosans increases with concentration of sodium hydroxide up to $6 \%$ at $165^{\circ} \mathrm{C}$ and it remains constant up to $18 \%$ sodium hydroxide concentration, after that it decreases rapidly, may be as a result of degradation of cellulose. The resistance of the residual pentosans in alkaline treatment is explained by McKinney by stating that some of the wood hemicelluloses were originally chemically bound to lignin by a glycoside linkage $(\beta$ phenylglycosidic type) that is broken during alkaline treatment with simultaneous formation of anhydrohemicelluloses, cross-linked with celluloses by trans-glycosidation reaction [15]. Therefore, $18 \%$ of sodium hydroxide concentration may be considered as an optimum dose of alkali for further processing at which maximum screened yield was obtained as shown in Fig. 1.

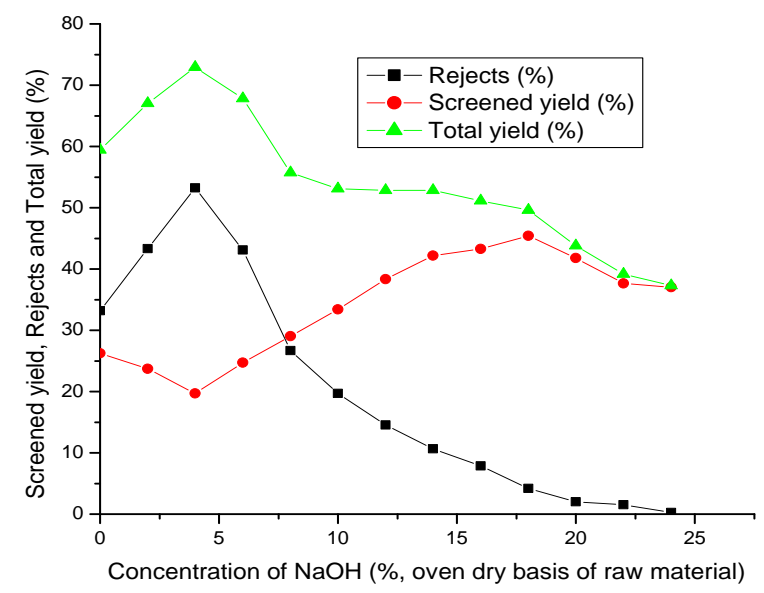

Fig.1. Effect of concentration of sodium hydroxide on screened yield rejects and total yield.

\section{Mechanism of repolymerisation of lignin during auto hydrolysis}

The $\mathrm{pH}$ of the medium during auto hydrolysis was acidic (acetic acid formation by acetylated xylan) in nature owing to which carbonium ions were generated at $\mathrm{C}_{\alpha}$-carbon atom (Fig. 2), as intermediate which leads to lignin repolymerisation more or less simultaneously with lignin depolymerisation [16]. The reactivity of $\mathrm{C}_{\alpha}$-carbon atom is more than that of $\mathrm{C}_{\beta}$-carbon atom and $\mathrm{C}_{\gamma}$-carbon atom because carbonium ions generated at $\mathrm{C}_{\alpha}$-carbon atom is resonance stabilised. The more stabilised carbonium ions generated first and reaction follows unimolecular elimination reaction ( $E_{1}$ reaction). In $\beta-O-4$ structure, the carbonium ion may react further with cleavage of the $\beta$ ether linkage and the formation of Hibbert ketones takes place by analogy with the acidolysis reaction. In the presence of other electron rich carbon atoms such as the $\mathrm{C}_{2} / \mathrm{C}_{6}$ present in guaiacyl and syringyl rings (identified by FT-IR spectroscopy), condensation may, however, compete with the acidolysis leading to repolymerisation of the lignin [2, 16-18]. Therefore, percentage of lignin (13.22\%, oven dry basis of raw material) was found to be almost same in auto hydrolysed sample as raw material (14.01\% oven dry basis as klason lignin).

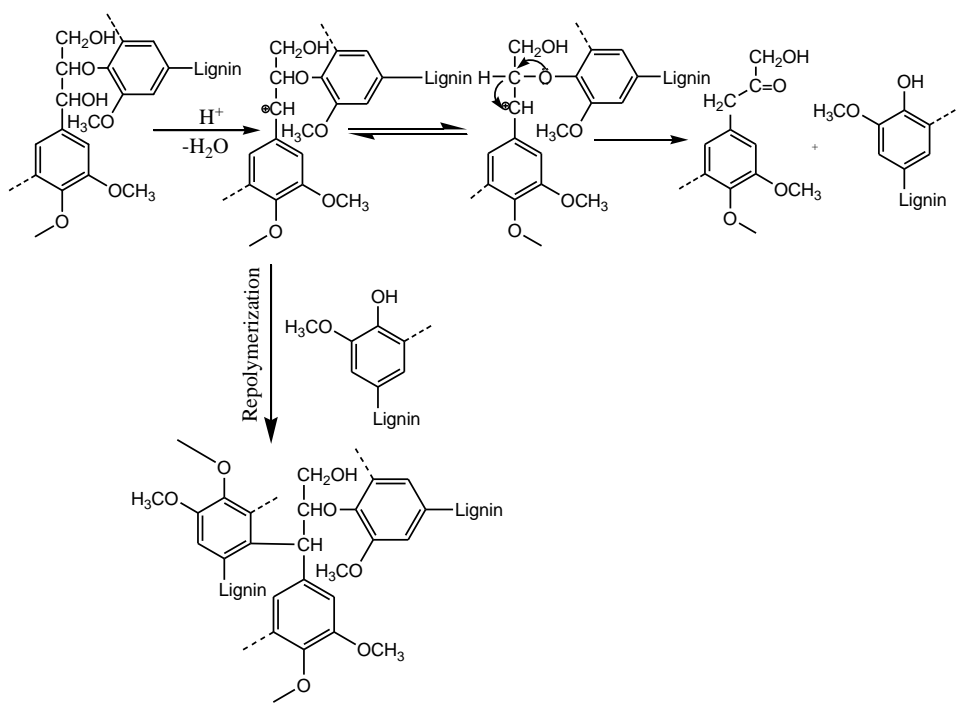

Fig.2. Reaction showing the lignin depolymerisation of $\beta$-O-4 structure and lignin repolymerisation involving reactive aromatic carbon.

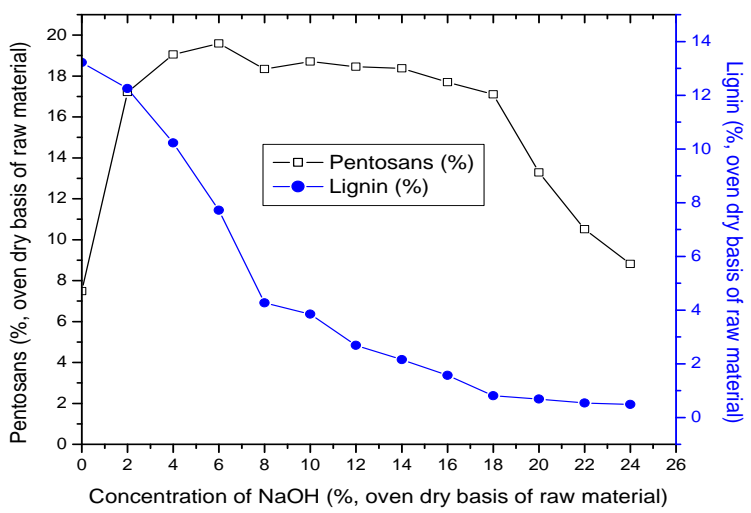

Fig.3. Effect of concentration of sodium hydroxide on pentosans and lignin content.

\section{Suppression of lignin repolymerisation}

The coincident depolymerisation and repolymerisation of lignin during an auto hydrolysis treatment of corn cob are undesirable reactions since they will lead to an increase in 
the heterogeneity of the resulting material. Additionally, solubility and reactivity properties will be depressingly affected. Since, the carbonium ions formed under acidic conditions are the intermediates for both reactions, broken up the $\mathrm{pH}$-conditions of the auto hydrolysis treatment towards the alkaline side could be one way to reduce the formation of carbonium ions and inhibit severe structural changes. The addition of an efficient scavenger for carbonium ions seems to be a better alternative. The presence of sodium hydroxide during the treatment process can be expected to result in an efficient suppression of all acidolysis-related reactions in the lignin. The alkali treatment cleaves the $\beta$-alkyl- aryl ether bonds ( $\beta$-O-4 linkages) in lignin via the formation of an epoxide intermediate with an intramolecular nucleophilic displacement of the $\beta$-phenoxide by either the $\alpha$ - or $\gamma$ alkoxide formed from the alcohol in strong base [19-20]. Subsequent nucleophilic attack by hydroxide cleaves the epoxide ring and produces a trihydroxy propane structure as shown in Fig. 4.
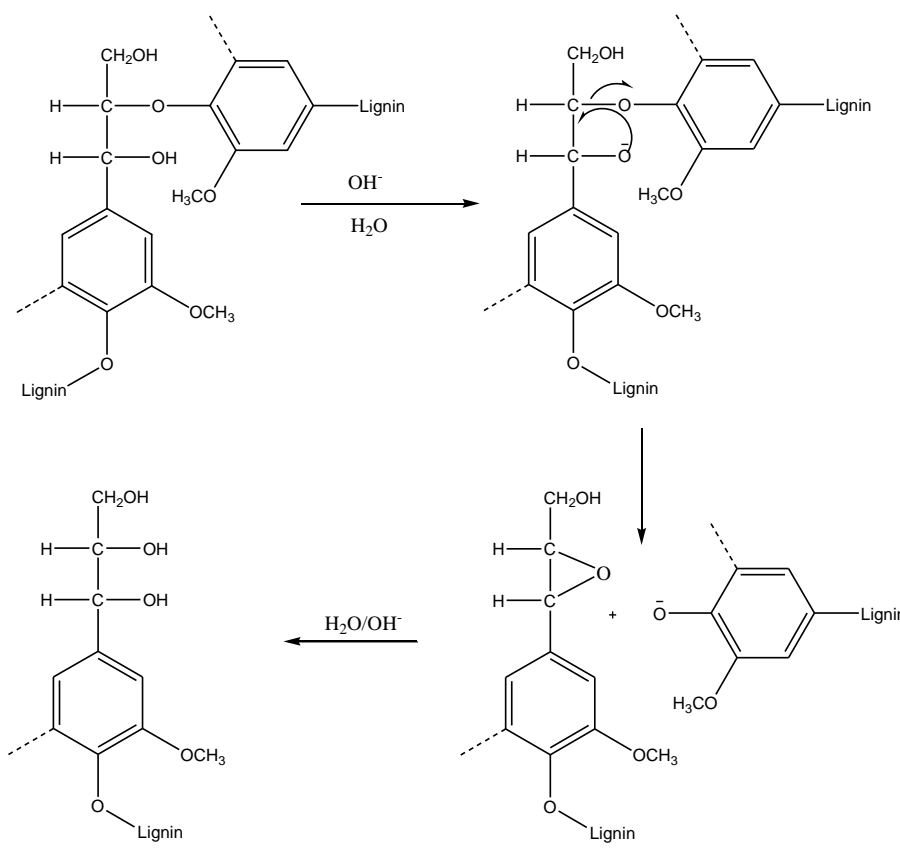

Fig. 4. Reaction schemes illustrating the reaction between a lignin structure and sodium hydroxide during alkaline treatment.

From Fig. 3, it is demonstrated that depolymerisation of lignin takes place sharply up to $18 \%$ and after that it remains constant. After $18 \%$ alkali charge, degradation of cellulose may also be taken place. Therefore, $18 \%$ of sodium hydroxide concentration may again be considered as an optimum dose of alkali for further processing.

\section{Fourier Transform Infrared (FT-IR) spectroscopy of corn cob klason lignin}

Infrared spectroscopy in the near IR region (wave numbers: $4000-500 \mathrm{~cm}^{-1}$ ) is a useful physical method for characterizing lignin and its derivatives. While the infrared spectrum is a characteristic property of compounds with exactly known structures, there are several uncertainties with the interpretation of lignin IR spectra.

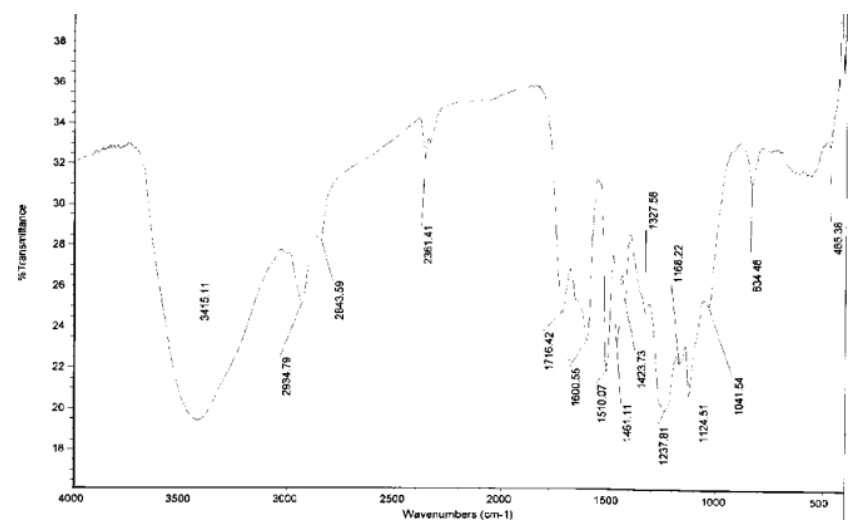

Fig. 5. Fourier transforms infrared (FT-IR) spectroscopy of corn cob klason lignin.

Fig. 5 show several major absorption bands representing the typical structure of lignin. The characteristic bands locating in $1424,1461,1510$ and $1601 \mathrm{~cm}^{-1}$ indicate the presence of aromatic rings and $\mathrm{C}-\mathrm{H}$ deformation bonds in the samples. The appearance of the single band at the 1328 $\mathrm{cm}^{-1}$ shows the C-O stretching of phenol and syringyl groups in the corn cob lignin [21]. The appearance of carbonyl group at $1716 \mathrm{~cm}^{-1}$ indicates that $\mathrm{C}=\mathrm{O}$ bond is not in conjugation with the aromatic rings [21]. The absorption at $2935 \mathrm{~cm}^{-1}$ and $2843 \mathrm{~cm}^{-1}$ corresponds to the $\mathrm{C}-\mathrm{H}$ stretching vibration of methoxy group. The characteristic band located at $3415 \mathrm{~cm}^{-1}$ indicates $\mathrm{O}-\mathrm{H}$ stretching of phenolic hydroxyl group [22], shift slightly lower than O-H stretching of phenolic hydroxyl groups of the guaiacyl and syringyl rings (3420-3530 $\left.\mathrm{cm}^{-1}\right)$, involved chiefly in intramolecular H-bonding [23]. Moreover, the intensive bands located at $1328 \mathrm{~cm}^{-1}$ and $1042 \mathrm{~cm}^{-1}$ arise from the aromatic $\mathrm{C}-\mathrm{H}$ in-plain deformation for typical syringyl band (syringyl ring breaking) [21] and guaiacyl band [24] respectively. Additionally, the absorption band in the region of $1124 \mathrm{~cm}^{-1}$ represents the characteristic group of $\beta$ $\mathrm{O}-4$ ether bond [25]. Therefore, by above exploration it may be interpreted that the corn cob lignin has major component as both syringyl and guaiacyl type as shown in Fig. 6.

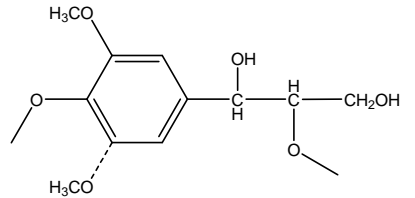

(a)

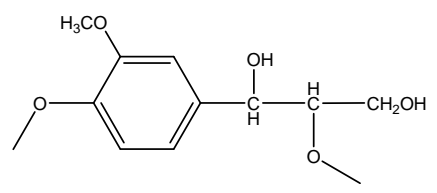

(b)
Fig. 6. (a) syringyl and (b) guaiacyl monomer units of corn cob lignin.

\section{Treatment selectivity}

On the basis of the above studies, the process conditions were optimised to obtain maximum yield and minimum chemical consumption. Based on experimental studies an alkali dose of $18 \%$ of $\mathrm{NaOH}$ concentration was found to be optimum for chemical treatment of corn cobs raw material. 
The samples obtained at the optimized condition were delignified with acidified sodium chlorite solutions and dried in vacuum oven. The obtained powder after delignification and drying was further screened from 270 $(53 \mu \mathrm{m})$ mesh size for the determination of $\alpha-, \beta-$, and $\gamma-$ cellulose by using TAPPI Standard Test Methods T 203 $\mathrm{cm}-99$. The results are shown in Table 4.

Table 4. Chemical Composition of Alkali Treated Holocellulose, oven dry basis.

\begin{tabular}{ccc}
\hline $\begin{array}{c}\alpha \text {-cellulose } \\
(\%)\end{array}$ & $\begin{array}{c}\beta \text {-cellulose } \\
(\%)\end{array}$ & $\begin{array}{c}\gamma \text {-cellulose } \\
(\%)\end{array}$ \\
\hline 72.75 & 25.19 & 02.06 \\
\hline
\end{tabular}

It may be concluded from Table 4 that almost all $\gamma$ cellulose is removed and solid residue enriched in $\alpha$ cellulose $(72.75 \%)$ and $\beta$-cellulose $(25.19 \%)$ only. Powders thus obtained were further characterised by X-ray Diffraction (XRD), Fourier Transform Infrared (FT-IR) and Scanning Electron Microscopy (SEM) technique.

FT-IR Spectroscopy of corn cob delignified raw material (cellulose I) and alkali treated corn cob-based nanoparticles (cellulose II)

FT-IR spectroscopy is a powerful tool for studying the physico-chemical and conformational properties of polysaccharides. In addition to X-ray and electron diffraction studies, FT-IR spectroscopy makes it possible, in particular, to solve the problems of identification of polysaccharides, to confirm their purity, to carry out semiquantitative functional analyses, to determine structure, and to investigate complexing and intermolecular interactions [26]. The main peak of FT-IR spectra of the delignified raw material, holocellulose (cellulose I) and alkali treated corn cob nanoparticles (cellulose II) are shown in Fig. 7. The analysis of FT-IR data shows that the holocellulose (cellulose I) has most significant absorption peak at 1734 $\mathrm{cm}^{-1}$ relates to $\mathrm{C}-\mathrm{O}$ stretching of carbonyl group [27] which was disappeared in alkali treated corn cob nanoparticles (cellulose II). The disappearance of peak in cellulose II indicates that the acetyl group of acetylated xylan (i.e. hemicelluloses) is removed almost completely by alkali treatment $(18 \% \mathrm{NaOH}$, on oven dry basis) at elevated temperature $\left(165^{\circ} \mathrm{C}\right)$. A broad absorption band in the range of $3420-3424 \mathrm{~cm}^{-1}$ that can be attributed to the $-\mathrm{OH}$ stretching associated to polar groups linked through intraand intermolecular hydrogen bonding [28] and the symmetric C-H stretching vibration band is found at 2900$2913 \mathrm{~cm}^{-1}$ owing to $\mathrm{CH}_{2}$ and $\mathrm{CH}_{3}$ group [29]. Furthermore, the band in the range $1160-1167 \mathrm{~cm}^{-1}$ is characteristic of glycosidic groups and attributed to $\mathrm{C}-\mathrm{O}, \mathrm{C}-\mathrm{O}-\mathrm{C}$, stretching and $\mathrm{C}-\mathrm{OH}$ bending vibration in arabinoxylan structure [26]. Also, there is an increase in the intensity of $\mathrm{C}-\mathrm{O}-\mathrm{C}$ ester stretching band at $1167 \mathrm{~cm}^{-1}$ as a result of the esterification. The IR band shifted to higher frequency $\left(1167 \mathrm{~cm}^{-1}\right.$ ) for cellulose II (mainly cellulose) confirm that crystalline content increases in comparison to cellulose I [30]. In addition, a sharp absorption peak appeared at 1115 $\mathrm{cm}^{-1}$ in cellulose II is further indicative of high cellulosic content. A sharp band at $1638-1642 \mathrm{~cm}^{-1}$ was also detected and attributed to $\mathrm{H}-\mathrm{O}-\mathrm{H}$ stretching, which occurs mainly in the amorphous state, and crystalline spectra measured in $\mathrm{KBr}$ which belongs to the absorbed water molecules associated with the cellulosic fibers [24, 31- 32]. The band at $1430 \mathrm{~cm}^{-1}$, assigned to $\mathrm{H}-\mathrm{CH}$ and $-\mathrm{OCH}$ in-plane bending vibrations in both cellulose I and cellulose II [33]. In addition, an absorption band near $1375 \mathrm{~cm}^{-1}$ is detected owing to the $\mathrm{C}-\mathrm{H}$ bending vibration present in cellulose and hemicellulose chemical structures [26]. The prominent peak at $1046-1036 \mathrm{~cm}^{-1}$ is attributed to the C-C, C-O stretching vibration [24] and $\mathrm{C}-\mathrm{OH}$ bending vibration [32] in both cellulose I and cellulose II. Finally, a sharp band at $899 \mathrm{~cm}^{-}$ 1 , which is typical of $\beta$-glycosidic linkages between the sugar units in hemicelluloses, was detected in the anomeric region [34] but these band is shifted to $896 \mathrm{~cm}^{-1}$ in alkali treated corn cob particles (cellulose II) with increased intensity, may further be suggestive of increased crystallinity. These peaks match well with spectra of cellulose.

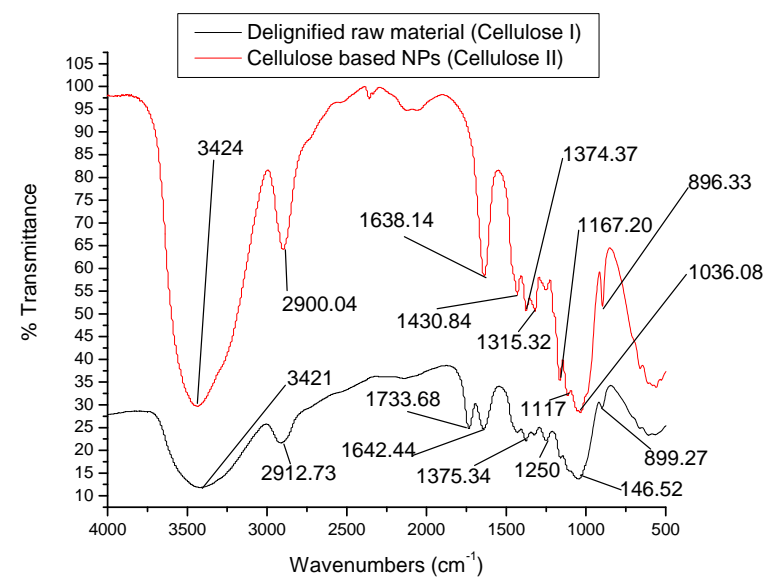

Fig.7. Comparison between FT-IR spectra of corn cob delignified raw material, holocellulose (cellulose I) and alkali treated corn cob cellulose based nanoparticles (cellulose II).

\section{$X$-ray diffraction $(X R D)$ analysis}

From Fig. 8 it was determined that the crystalline content of nanoparticles increased from $37 \%$ (lignified as well as delignified raw materials) to $48 \%$ (nanoparticles). The crystallinity was found to increase owing to smaller particle size [35] and removal of amorphous substances such as lignin, hemicelluloses, and extractives.

The XRD pattern of corn cob-based nanoparticles showed several relatively strong reflection peaks. The main diffraction peaks were assigned: $2 \theta=16.230^{\circ}(\mathrm{d}=$ 5.60778), $22.221^{\circ}(\mathrm{d}=3.99738)$, and $34.787^{\circ}(\mathrm{d}=$ 2.57686). The average particle size may be estimated by using Scherrer's equation (1).

$D=K \lambda / \beta \cos \theta$

where $K$ is the shape factor, $\lambda$ is the $\mathrm{X}$-ray wavelength (1.54060 $\AA$ ), $\beta$ is the line broadening at half the maximum intensity (FWHM) in radians, $\theta$ is the Bragg's angle, and $D$ is the mean size of the ordered (crystalline) domains. The dimensionless shape factor has a typical value of about 
0.93 , but varies with the actual shape of the crystallite. The reflecting peaks at $2 \theta=22.221^{\circ}$ and $34.787^{\circ}$ are used to estimate the average size ( $\sim \mathrm{nm}$ and $\sim 13 \mathrm{~nm}$ respectively) of the corn cob-based nanoparticles.

\section{Transmission electron microscopy (TEM) analysis}

TEM photographs (Fig. 9) show that the average particle size was $22 \mathrm{~nm}$, and the corresponding electron diffraction pattern showed only diffused signals, as expected for amorphous materials.

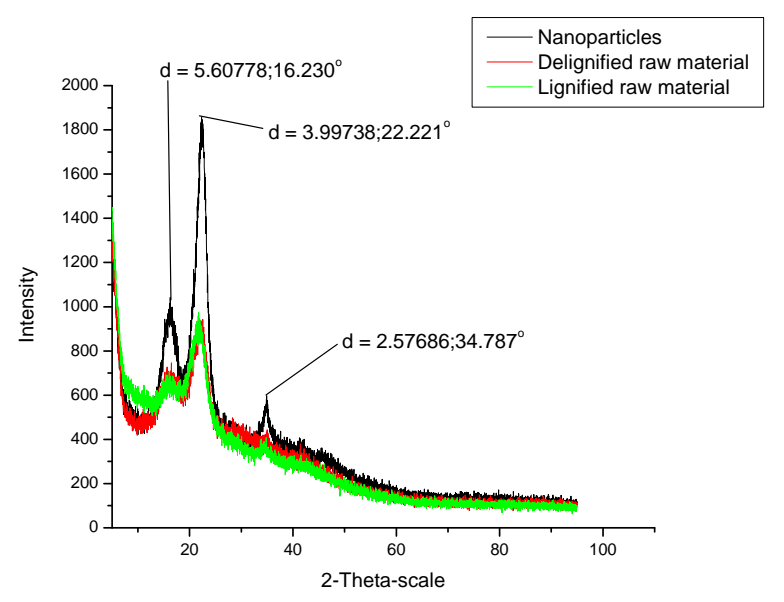

Fig. 8. X-ray diffraction curve of lignified \& delignified raw material and corn cob-based nanoparticles.
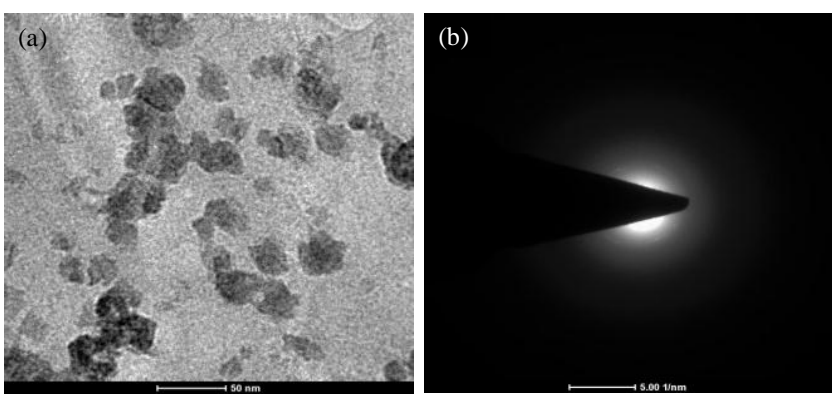

Fig. 9. (a) Representative TEM image of corn cob based nanoparticles (scale bar represents $50 \mathrm{~nm}$ ) and (b) the corresponding diffraction pattern.

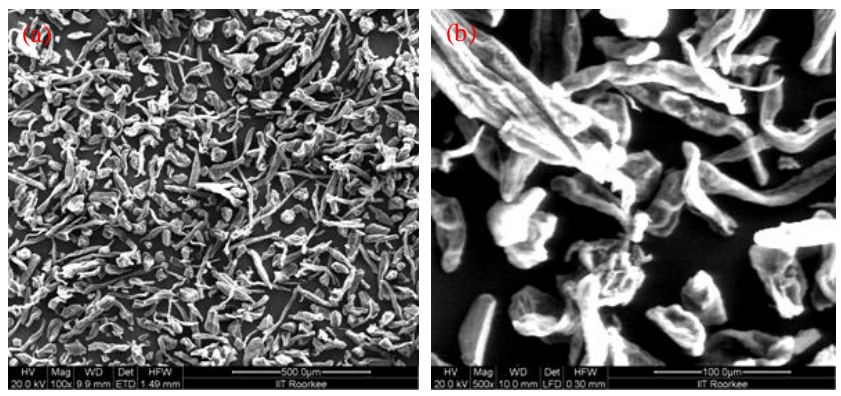

Fig. 10. SEM image (a) Aggregated corn cob based nanoparticles (scale bar represents $500 \mu \mathrm{m}$ ) and SEM image (b) Same sample at lower magnification (scale bar represents $100 \mu \mathrm{m}$ ).
Scanning electron microscopy analysis

Scanning electron microscopy (SEM) gives the morphological evidence of the CNPs. Fig. 10 shows clusters of particles, with varying structures, having an average diameter ranging from $24 \mu \mathrm{m}$ to $200 \mu \mathrm{m}$, which is attributed to aggregation of particles through a solid bridging mechanism. In order to keep free-flowing nanoparticles separate, then they must be prepared and stored in a liquid medium, designed to facilitate sufficient interparticle repulsion forces to prevent aggregation.

\section{Conclusion}

The main purpose of the above study was to obtain and characterise CNPs prepared from corn cobs. It is demonstrated that the functional groups in the spectrum showed the polysaccharide structure of cellulose. Sorption of xylan (hemicelluloses) on to cellulose is also confirmed by FT-IR analysis. By FT-IR analysis, it is also confirmed that the corn cob contains syringyl and guaiacyl type lignin as major components in corn cob raw material. There was a propensity for the crystallinity to increase as the particle sizes became smaller so, crystalline content of nanoparticles is increased in comparison to corn cob raw material as confirmed by both FT-IR and X-ray diffraction analysis. Particles size is estimated in the range of approximately $22 \mathrm{~nm}$ as determined by Transmission Electron Microscope (TEM) technique, but in solid state, particles can be agglomerated by solid bridging mechanism as seen in SEM micrographs. In view of the above reported results, the preparation of CNPs from corn cobs can be an important issue concerning to the environment because a green polymer from a renewable source was in fact a great contestent for the pharmaceutical industrial research and development sectors. These CNPs under study can have promising use specifically as internal body drug delivery systems.

\section{Acknowledgement \\ One of the authors, Mr. Samit Kumar is highly thankful to the Ministry of Human Resource Development (MHRD), New Delhi, India for the} financial research grant for pursuing the Ph.D. work.

\section{References}

1. Helbert, W.; Cavaille, J.Y.; Dufresne. A. Polymer Composites 1996, 17,604 .

2. Kumar, S.; Upadhyaya, J.S.; Negi, Y.S. BioResources 2010, 5, 1292.

3. Wegner, T.H.; Jones, P.E. Cellulose 2006, 13,115.

4. Kopecný, J.; Hajer, J.; Mrázek, J. Folia Microbiol 2004, 49, 175.

5. Wedekind, K.J.; Mansfield, H.R.; Montgomery, L. Applied and environmental microbiology 1988, 54, 1530.

6. Ratna, V.; Prabhakaran, L. Prushothaman. M. Targeted drug delivery systems 2010, 8, 2.

7. Moore, W.E.; Cato, E.P.; Holdeman, L.V. American Journal of Clinical Nutrition 1978, 31, S33.

8. Cummin, J.H.; Proceedings of the Nutrition Society 1984, 43, 35.

9. Miller, T.L.; Wolin, M.J. The American Journal of Clinical Nutrition 1979, 32, 164.

10. Heller, S. N.; Hackler, L.R.; Rivers, J.M.; Soest, P.J.V.; Roe, D.A.; Lewis, B.A.; Robertson, J. The American Journal of Clinical Nutrition 1980, 33, 1734.

11. Hummel, F.C.; Shepherd, M.L.; Macy, I.G. JN The Journal of Nutrition 1942, 25, 59.

12. Ebringerova, A.; Hromadkova, Z.; Kacurakova, M.; Antal, M. Carbohydrate Polymers 1994, 24, 301.

13. Stephens, C.H.; Whitmore, P.M.; Morris, H.R.; Bier, M.E BioMacromolecules 2008, 9, 1093. 
14. Heitz, M.; Carrasco, F.; Rubio, M.; Chauvette, G.; Chornet, E. The Canadian Journal of Chemical Engineering 1986, 64, 647.

15. McKinney, J. W. Paper Trade J. 1946, 122, 58.

16. Jiebing, Li.; Henriksson, G.; Gellerstedt, G. Bioresource Technology 2007, 98, 3061.

17. Lora, J. H.; Wayman, M. Tappi 1979, 61, 47.

18. Robert, D.; Gellerstedt, G.; Bardet, M. Nordic Pulp Pap. Res. J. 1986, $1,18$.

19. Filley T.R.; Minard, R.D.; Hatcher, P.G. Organic Geochemistry 1999, 30, 607

20. Ellis, A.V.; Wilson, M. A.; Forster, P. Ind. Eng. Chem. Res. 2002, 41, 6493.

21. Pasquali, C.E. L.; Herrera, H. Thermochimica Acta 1997, 293, 39.

22. Liu, Q.; Wang, S.; Zheng, Y.; Luo, Z.; Cen, K. J. Anal. Appl. Pyrolysis 2008, 82, 170.

23. Gol'man, L. P.; Reznikov, V. M. Zhurnal Prildadnoi Spektroskopii 1973, 19, 1128.

24. Xiao, B.; Sun, X.F.; Sun, R. C. Polymer Degradation and Stability 2001, 174, 307.

25. Nada, Abd-Alla M. A.; Yousef, M. A.; Shaffeib, K. A.; Salah, A. M. Polymer Degradation and Stability 1998, 62, 157.

26. Sun, R.C.; Fang, J.M.; Goodwin, A.; Lawther, J.M.; Bolton, A.J. Carbohydrate Polymers 1998, 37, 351.

27. Tjeerdsma, B.F.; Militz, H. Holz als Roh- und Werkstoff 2005, 63, 102.

28. Sun, X.F.; Xu, F.; Zhao, H.; Sun, R.C.; Fowler, P.; Baird, M.S. Bioresource Technology 2005b, 96, 1342.

29. Ren, Jun-Li.; Peng, F.; Sun, R.C. Carbohydrate Research 2008, 343 , 2776.

30. Colom, X.; Carrillo, F.; Nogues, F.; Garriga, P. Polymer Degradation and Stability 2003, 80, 543

31. Sain, M.; Panthapulakkal, S. Industrial Crops and Products 2006, $23,1$.

32. Oliveira, E.E.; Silva, A.E.; Júnior, T.N.; Gomes, M.C.S.; Aguiar, L.M.; Marcelino, H.R.; Araújo, I.B.; Bayer, M.P.; Ricardo, N.M.P.S.; Oliveira, A.G.; Egito, E.S.T. Bioresource Technology 2010, 101, 5402.

33. Satyamurthy, P.; Jain, P.; Balasubramanya, R.H., Vigneshwar, N. Carbohydrate Polymers 2010, 83, 122.

34. Sun, X.F.; Xu, F.; Sun, R.C.; Geng, Z.C.; Fowler, P.; Baird, M.S. Carbohydrate Polymers 2005a 60, 15

35. Zhang, J.; Elder, T.J.; Pu, Y.; Ragauskas, A.J. Carbohydrate Polymers 2007, 69, 607. 